\title{
PENGARUH ZIKIR TERHADAP KETENANGAN DAN KEBAHAGIAAN MANUSIA, PERSPEKTIF QURANI
}

\author{
Mohammad Bisri \\ Faculty of Psychology State University of Malang \\ moh.bisri.fppsi@um.ac.id
}

\begin{abstract}
Humility and human happiness are a very important aspect. Many factors affect human serenity and happiness, such as prayer, zakat and charity, fasting, pilgrimage and dhikr. but only one that is easy for everyone throughout the world in various circumstances and environment and has a very decisive influence on human happiness that is dhikr to Allah. On the contrary, human beings no longer use it to recite to Allah, then suddenly his happiness is pulled out from his bosom; it's just gone missing its memory. There was a sad feeling, his chest suddenly felt tight and narrow, not even infrequently his life became meaningless.

Keywords: remembrance, happiness, Quran
\end{abstract}

Abstrak: Kerendahan hati dan kebahagiaan manusia adalah aspek yang sangat penting. Banyak faktor yang memengaruhi ketenangan dan kebahagiaan manusia, seperti sholat, zakat, dan amal, puasa, ziarah, dan zikir. tetapi hanya satu yang mudah bagi semua orang di seluruh dunia dalam berbagai keadaan dan lingkungan dan memiliki pengaruh yang sangat menentukan pada kebahagiaan manusia yang berdzikir kepada Allah. Sebaliknya, manusia tidak lagi menggunakannya untuk membaca kepada Allah, lalu tiba-tiba kebahagiaannya ditarik keluar dari dadanya; itu baru saja hilang ingatannya. Ada perasaan sedih, dadanya tiba-tiba terasa kencang dan sempit, bahkan tak jarang hidupnya menjadi tak berarti.

Keywords: Zikir, kebahagiaan, Quran

\section{A. Pendahuluan}

Ketenangan dan kenyamanan merupakan ekspresi kebahagiaan yang paling umum dirasakan orang. Ekspresi lain seperti perasaan enak, rasa senang dan perasaan lainnya tidak dibahas disini. Beberapa faktor yang berkaitan dengan kebahagiaan yang memiliki hubungan sangat kuat adalah berzikir, yakni aktifitas ibadah verbal dan spiritual yang diekspresikan dengan pengucapan kalimat tertentu dengan cara tertentu dengan menggunakan lisan yang bisa didengar oleh telinga, atau dengan menggunakan qolbu, hati untuk menyebut-nyebut asma Allah tanpa suara lahiriah. 
Menurut guru besar Spiritual dibidang menejemen Qolbu TQN Suryalaya, ${ }^{1}$ bahwa puncak pencarian kebahagiaan yang lebih kekal bagi manusia adalah mendekat, bersama Allah, dengan berzikir kepada Allah. Karena dengan zikir itulah hati, jiwa manusia menjadi tenang. Sebaliknya jika hati manusia tidak digunakan untuk berzikir kepada Allah manusia akan susah, gundah tidak bahagia. Bahkan jika orang tidak menggunakan hatinya untuk berzikir kepada Allah, maka dada orang itu akan susah, sedih, dadanya terasa sesak.

Karena itulah maka fokus bahasan pada kesempatan ini akan dibahas lebih mendalam bagaimana pengaruh zikir bagi kebahagiaan manusia. Fokusnya pada penelusuran Quran dan tafsirnya. ${ }^{2}$ Semua diselesksi berkaitan dengan zikir dan manfaatnya untuk dikomparasikan dengan pandangan para praktisi sufi.

\section{Dasar Dan Alasan Orang Melakukan Zikir Kepada Allah}

Perkembangan ruhaniah manusia yang paling tinggi adalah ketenangan dan kebahagiaan. Terjadinya entitas, yaitu keutuhan laku dan tercapainya integritas kepribadian, yaitu, keserasian dimensi fisik, mental dan spiritual manusia. Ketimpangan salah satunya akan menimbulkan masalah, seperti kekecewaan, kegetiran, sampai kepada kepahitan hidup. Meskipun begitu asalkan spiritualnya dapat menerimanya dengan lapang dada, maka masalah akan dapat diurai dan kebahagian akan dapat dicapai.

Banyak orang yang ingin bahagia hidupnya, ingin tenang batinnya akan tetapi banyak orang sampai ajal menjelang ketenangan batin yang dia inginkan belum juga didapatkannya. Orang barat Amerika Utara dan Eropa Barat yang memiliki kekayaan material melimpah dan kekuasaan territorial yang luas, mungkin juga meraih banyak ketenaran, namun kebanyakan mereka tidak berhasil mencapai kebahagiaan yang kekal. Mereka mulai melirik cara-cara orang timur meraih ketenangan dan kebahagiaan hidup. Mereka sekarang sedang sibuk mempelajari tai-chi,

${ }^{1}$ Syeh Ahmad Shohibul Wafa Tajul 'Arifin, Uqudul Jumaan, Tanbih (Suryalaya: Yayasan Serba Bakti Pondok Pesantren Suryalaya dan Thoriqat Qodiriyyah Wan Naqsabandiyyah, 1975).

${ }^{2}$ Departemen Agama RI, Al-Quran dan Terjemahannya (Surabaya: Duta Ilmu, 2005); Mahmud Yunus, Tafsir Quran Karim, 20 ed. (Jakarta: Hidakarya Agung, 1983). 


\section{Pengaruh Zikir Terhadap Ketenangan Dan}

Kebahagiaan Manusia, Perspektif Qurani

chi-kung, yoga untuk mencapai kebahagiaan dan ketenangan hidup. Di negara-negara Amerika Utara dewasa ini mulai banyak orang belajar zikir sebagai teknologi dan solusi dalam mencapai ketenangan dan kebahagiaan hidup.

Untuk mencapai kebahagiaan hakiki perlu jalan yang benar, cara atau teknologi yang tepat sebagaimana jalan, cara yang yang digunakan orang-orang sholeh sebagai yang ditunjukkan Tuhannya, sebagaimana yang difirmankan Allah dalam al-Quran Surat al-Maidah, 5: 35; yaitu agar orang beriman dapat bertaqwa, perlu mencari washilah yang tepat, dan berjuang keras menggunakan washilah tersebut agar diberi kemenangan dan berbahagia.

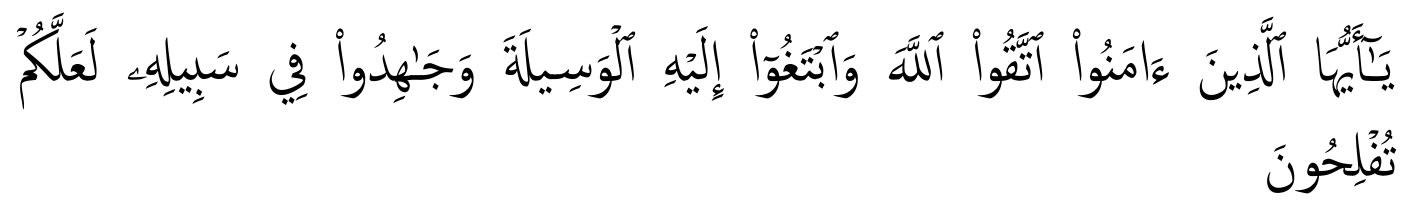

Hai orang-orang yang beriman, bertakwalah kepada Allah dan carilah jalan yang mendekatkan diri kepada-Nya, dan berjuanglah dengan sungguh-sungguh di jalan-Nya, agar supaya kamu mendapat keberuntungan (QS. Al-Maidah, 5: 35).

\section{Zikir mendatangkan ketenangan batin dan kebahagiaan Hati}

Banyak cara yang digunakan orang untuk memperoleh ketenangan hati seperti meditasi, yoga refresing di alam terbuka dsb. Namun tidak ada yang menyamai keektifan dan kecepatannya dengan zikir. Allah sendiri menegaskan bahwa zikir adalah satu-satunya cara untuk mencapai ketenangan batin.

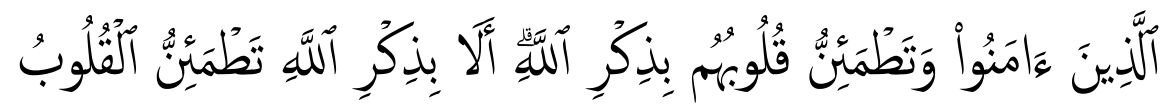

(yaitu) orang-orang yang beriman dan hati mereka manjadi tenteram dengan mengingat Allah. Ingatlah, hanya dengan mengingati Allah-lah hati menjadi tenteram.( QS. Ra'd, 13:28)

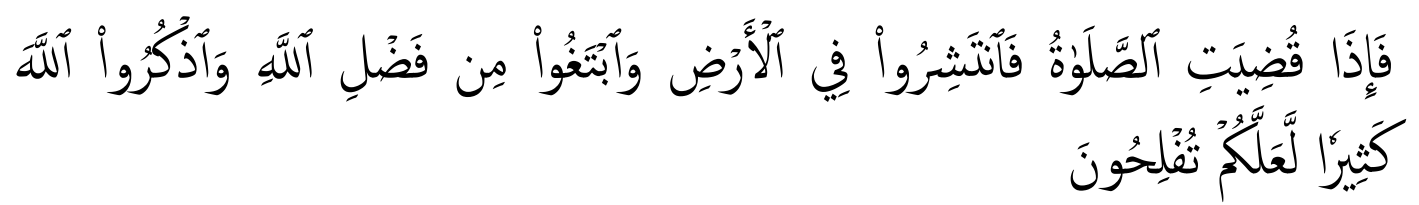

Apabila telah ditunaikan shalat, maka bertebaranlah kamu di muka bumi; dan carilah karunia Allah dan ingatlah Allah banyak-banyak supaya kamu beruntung.(QS. Al Jumuah, 62:10) 
Allah menjelaskan bahwa hanya dengan zikir (mengingat Allah) hati akan menjadi tenang.

\section{Tidak berzikir membuat dada sesak}

Banyak orang menyangka bahwa kesedihan, kekecewaan disebabkan oleh karena harapan dan keinginan yang tidak tercapai. Kebutuhan yang tidak terpenuhi, dan cita-cita gagal diraih. Namun hakikatnya adalah kesedihan, kesusahan terjadi karena masalah spiritual, ruhaninya jauh dari Tuhan, lupa tidak berzikir kepada Allah. Akibatnya adalah energi spiritualnya melemah, tidak memadai, sehingga tidak mampu untuk menjalani hidup. Karenanya dengan mendongkrak energi spiritual, maka manusia akan mampu menjalani hidup bagaimanapun beratnya. Sebaliknya energi spiritual yang lemah manusia tidak dapat mampu menanggung beban hidup betatapun kecilnya masalah yang sedang ditanggung.

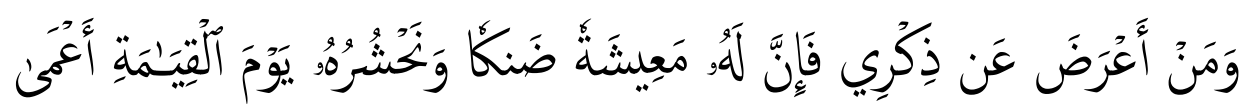

Siapa yang berpaling untuk mengingat Allah di dunia hatinya akan sesak dan di akhirat akan dibangkitkan dalam keadaan buta (QS. Toha, 20: 124)

\section{Zikir Berfungsi sebagai Pembersih Hati}

Rasulullah menjelaskan dalam hadisnya yang diriwayatkan oleh imam Baihaqi, bahwa segala sesuatu itu ada pembersihnya. Dan pembersih hati adalah zikir kepada Allah. (HR. Baihaqi). Hati yang bersih akan membuat hati berbahagia. Sebaliknya hati yang kotor membut hati tidak berbahagia, dan berakibat kepada kerugian. Sebagaimana Allah berfirman

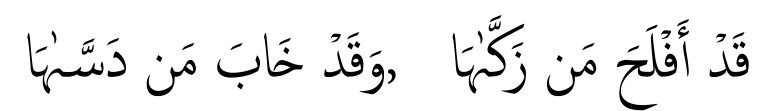

Sesungguhnya beruntunglah orang yang mensucikan jiwa itu. Dan sesungguhnya merugilah orang yang mengotorinya. (QS. Asy-Syam, 91: 9-10)

\section{Zikir Dapat Mendatangkan Keridhoan Allah}

Nabi diperintah Allah untuk berkumpul dengan jamaah zikir (QS. Al Kahfi, 18: 28), Nabi diwanti-wanti agar tidak berkumpul dengan orang- 
orang menuruti hawa nafsunya, hatinya dilalaikan untuk mengingat Allah, karena tergiur dunia

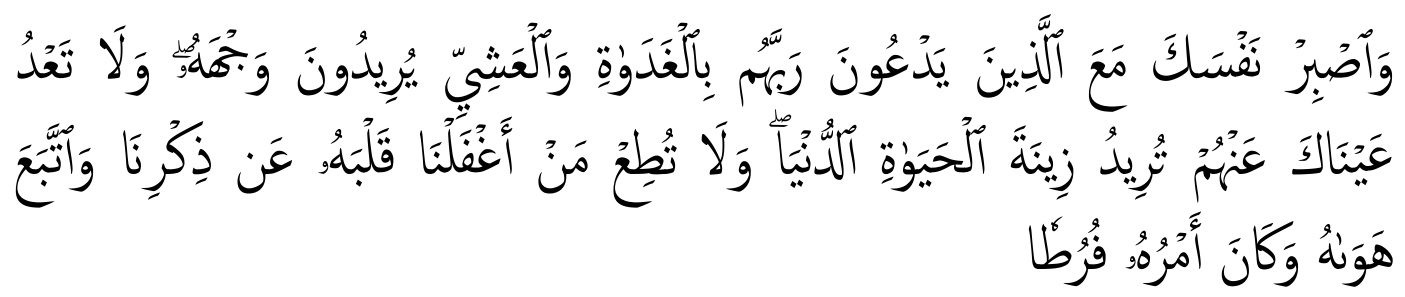

Dan bersabarlah kamu bersama-sama dengan orang-orang yang menyeru Tuhannya di pagi dan senja hari dengan mengharap keridhaan-Nya; dan janganlah kedua matamu berpaling dari mereka (karena) mengharapkan perhiasan dunia ini; dan janganlah kamu mengikuti orang yang hatinya telah Kami lalaikan dari mengingati Kami, serta menuruti hawa nafsunya dan adalah keadaannya itu melewati batas. (QS. Al Kahfi, 18: 28)

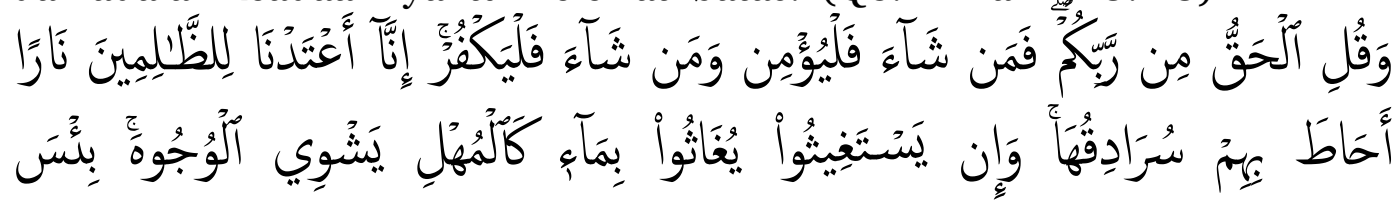

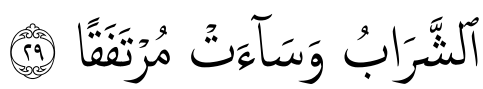

Dan katakanlah: "Kebenaran itu datangnya dari Tuhanmu; maka barangsiapa yang ingin (beriman) hendaklah ia beriman, dan barangsiapa yang ingin (kafir) biarlah ia kafir". Sesungguhnya Kami telah sediakan bagi orang orang zalim itu neraka, yang gejolaknya mengepung mereka. Dan jika mereka meminta minum, niscaya mereka akan diberi minum dengan air seperti besi yang mendidih yang menghanguskan muka. Itulah minuman yang paling buruk dan tempat istirahat yang paling jelek. (QS. Al Kahfi, 18: 29)

Contoh lagi ingin sabar dan sholat dengan baik dan benar juga sulit

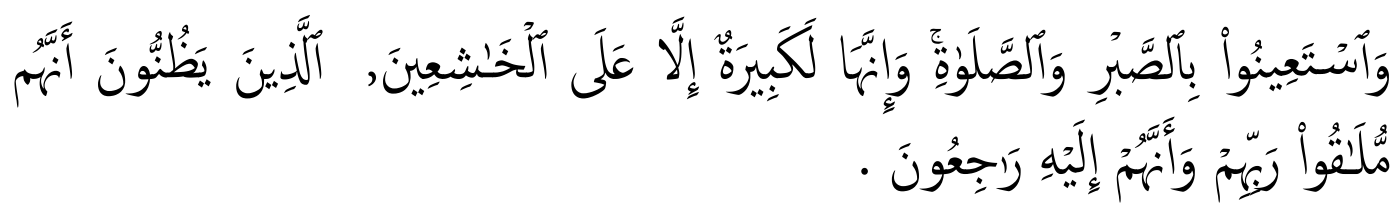

Jadikanlah sabar dan shalat sebagai penolongmu.Dan sesungguhnya yang demikian itu sungguh berat, kecuali bagi orang-orang yang khusyu', (yaitu) orang-orang yang meyakini, bahwa mereka akan menemui Tuhannya, dan bahwa mereka akan kembali kepada-Nya. (Q.S. AL Baqoroh, 2: 45-46).

Pendosa yang dadanya sempit dan sesak tentu ingin segera merasakan dadanya menjadi lapang dan bahagia.Untuk itu perlu ampunan dari Allah. Akan tetapi tidak akan diampuni jika dia tidak masuk daftar orang-orang yang taat, mencintai Allah. Padahal taat dan mencintai Allah 
tidaklah mudah dilakukan oleh kebanyakan orang. Sebagaimana yang dijelaskan Allah dalam QS. Ali Imron, 3: 31.
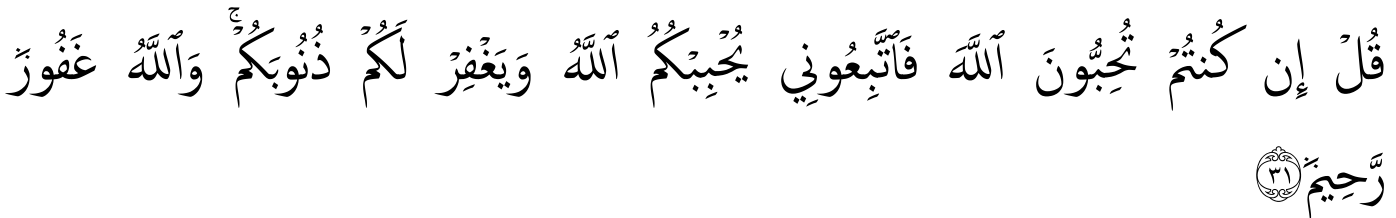

Katakanlah: "Jika kamu (benar-benar) mencintai Allah, ikutilah aku, niscaya Allah mengasihi dan mengampuni dosa-dosamu." Allah Maha Pengampun lagi Maha Penyayang.(QS. Ali Imron, 3: 31)

Apalagi yang khusnul khotimah tambah jauh lagi.Semua saran dan resep mendapatkan bahagia dan ketenangan batin di ambilnya, meskipun dengan harga yang sangat tinggi.Misalnya menumpuk harta, bekerja sampai habis waktunya, rekreasi dan belanja sampai habis terkuras tabungannya. Hasilnya adalah setelah mereka pulang dari rekreasi, sebagai contoh, maka yang mereka rasakan adalah rasa penat kepayahan, penderitaan dan penyesalan. Akan tetapi karena banyak manusia yang mengalami hal yang serupa, maka mereka tidak merasa tertipu atau merasa terlanjur telah mengambil keputusan yang keliru. Allah SWT telah mengingatkan bahwa hanya dengan bertaqwa saja manusia memperoleh kebahagiaan, dan hanya dengan berzikir kepada Allah saja manusia akan memperoleh ketenangan batin

\section{Sebab Manusia menolak ajakan Allah}

Sepanjang sejarah kehidupan manusia dalam mencari kebahagiaan dan ketenangan hidup dengan melakukan zikir sejak nabi Adam sampai sekarang hanya satu yang menghalangi manusia mengikuti ajakan Allah agar manusia berzikir kepadaNya, yaitu merasa lebih benar dari guru pembimbingnya.Sehingga dia berani membuat berbagai keputusan, bersikap yang berbeda bahkan berlawanan dengan ajakan Allah SWT. Sikap demikian oleh Allah disebut dalam firman-Nya dengan sikap menyombongkan diri (Q.S. Asshoffat, 37: 35).

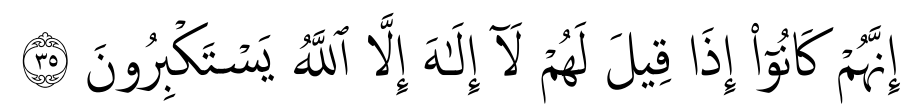

Artinya: Sesungguhnya mereka dahulu apabila dikatakan kepada mereka: "Laa ilaaha illallah" (Tiada Tuhan yang berhak disembah melainkan Allah) mereka menyombongkan diri (Q.S. Asshoffat, 37: 35). 


\section{Pengaruh Zikir Terhadap Ketenangan Dan}

Kebahagiaan Manusia, Perspektif Qurani

Orang berani bertindak maksiyat kepada Allah dengan sikap sombong karena belum mengenal Allah dengan benar, sehingga mudah terbujuk oleh bisikan syetan, sebagaimana Adam yang berani bertindak maksiyat, bahkan menentang, melanggar larangan Allah (QS. Al-A'rof, 7: 20)

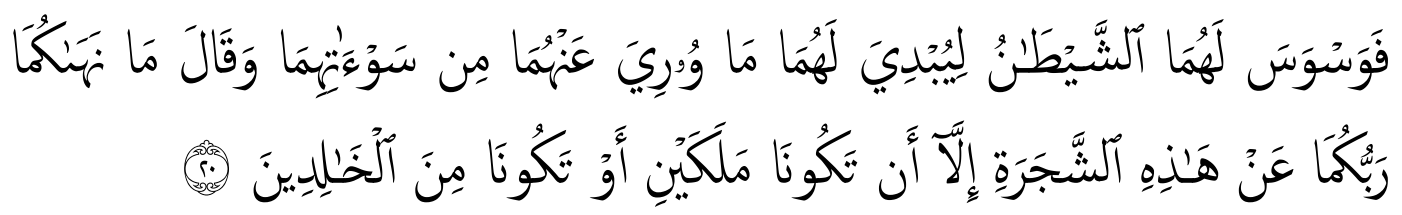

Maka syaitan membisikkan pikiran jahat kepada keduanya untuk menampakkan kepada keduanya apa yang tertutup dari mereka yaitu auratnya dan syaitan berkata: "Tuhan kamu tidak melarangmu mendekati pohon ini, melainkan supaya kamu berdua tidak menjadi malaikat atau tidak menjadi orang-orang yang kekal (dalam surga)".(Q.S. Al-A'raf, 7: 20).

Iblis ketika divonis oleh Allah sebagai makhluk terkutuk yang sesat akan dimasukkan ke dalam neraka yang kekal, Iblis sadar tidak kuasa menolak keputusan Allah itu, dia tidak mau mengakui kesalahannya, bahkan yang terjadi adalah sikap sombongnya semakin menjadi-jadi. Dia bahkan membuat Gand Desain dengan menghalangi seluruh manusia untuk beriman kepada Allah.Untuk memastikan rencana besarnya itu iblis bersumpah untuk mencari teman sebanyak-banyaknya di dalam neraka;

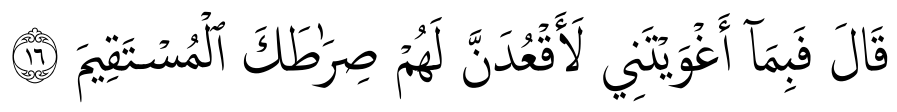

Iblis menjawab: "Karena Engkau telah menghukum saya tersesat, saya benar-benar akan (menghalang-halangi) mereka dari jalan Engkau yang lurus, (QS. Al A'raf, 7: 16)

Bahkan mengganggunya manusia dengan segala daya upaya dan cara;

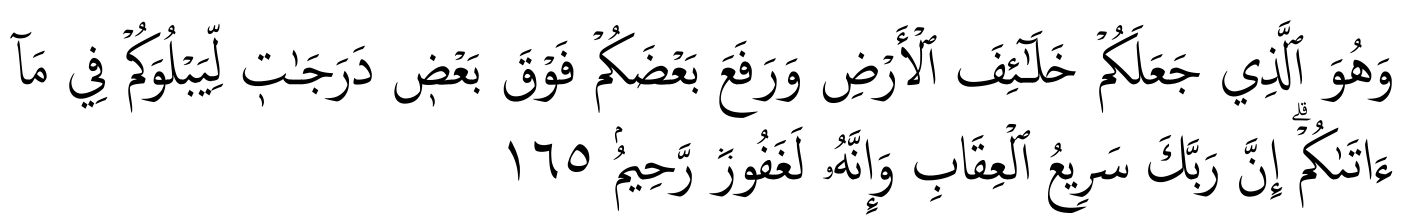

kemudian saya akan mendatangi mereka dari muka dan dari belakang mereka, dari kanan dan dari kiri mereka. Dan Engkau tidak akan mendapati kebanyakan mereka bersyukur (zikir).(QS. Al A’raf; 7: 17).

Syaithan dalam membujuk manusia dengan sikap yang sangat meyakinkan, rasional, kompeten dan profesional, sehingga kebanyakan 
manusia yang belum cukup ilmunya tentang hakikat ilahiyah akan terperangah oleh bujukan dan rayuan syetan. Karena ilmu yang hakiki tidak akan diperoleh oleh manusia kecuali dari Allah langsung (wahyu, ilham) kepada para Nabi dan para wali-walinya sebagai ulama pewaris para Nabi. Kebanyakan kaum muslimin atau orang awam yang tidak diberi Allah kompetensi khusus melakukan "booting-spiritual" (menghidupkan fungsi ruhaniahnya) sehingga bisa melakukan akses langsung kepada Allah SWT. Ruhani yang masih nutup tidak bisa berkomunikasi dengan Allah, dia tidak bisa berbicara dengan Allah dan sebaliknya dia tidak dapat mendengarkan pesan-pesan penting dari Allah. Bahkan Quran dibacapun tidak bisa merasuk kedalam lubuk hatinya. Ikhlas sulit, sholat khusyuk sulit, sabar apa lagi... makin jauh panggang dari api.

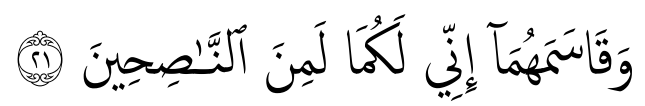

Dan dia (syaitan) bersumpah kepada keduanya. "Sesungguhnya saya adalah termasuk orang yang memberi nasihat kepada kamu berdua",(Q.S. Al-A'raf, 7: 21).

Orang yang tidak mau berzikir"Laa ilaaha illallah" disebabkan oleh sifat sombong.

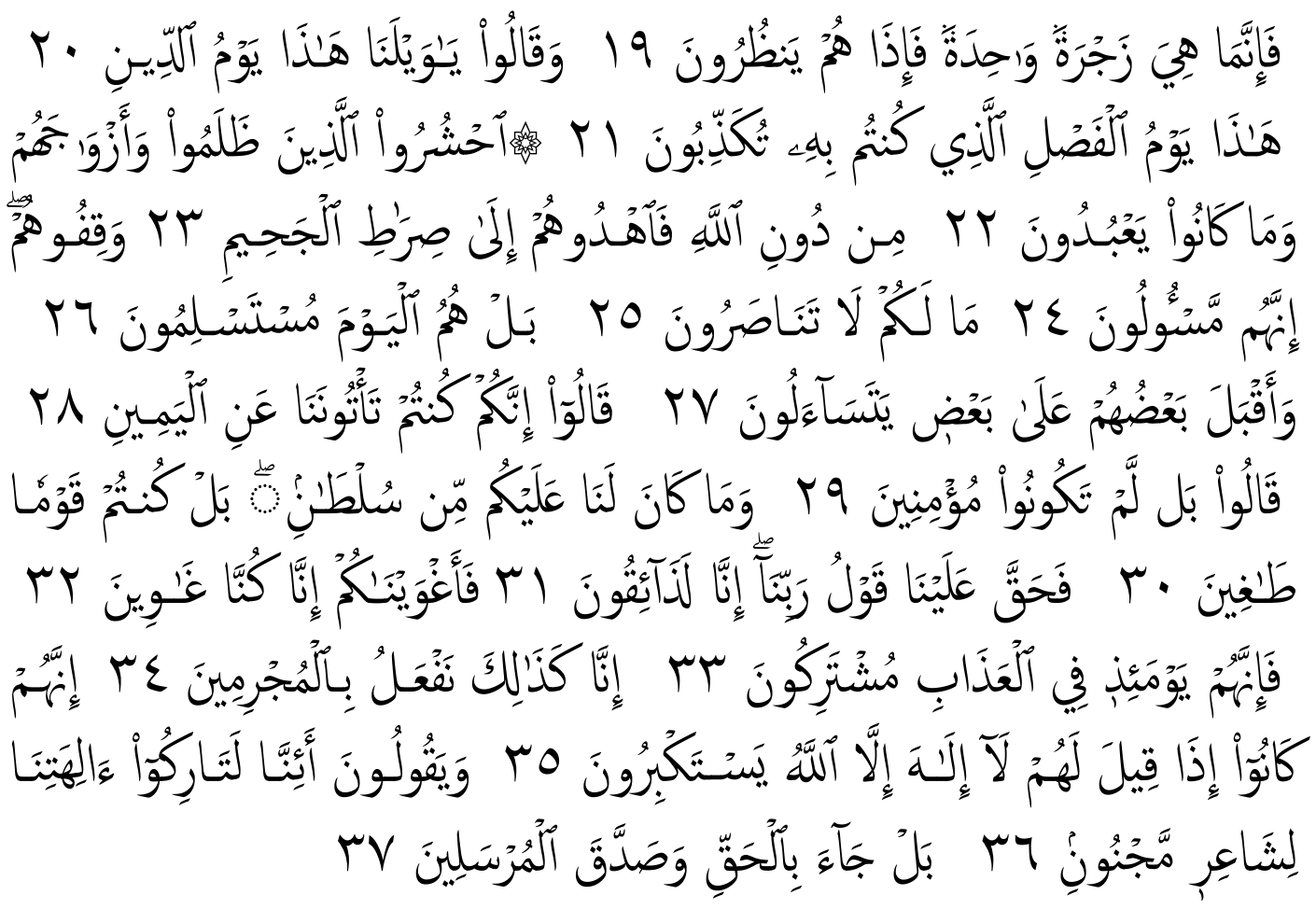




\section{Pengaruh Zikir Terhadap Ketenangan Dan}

Kebahagiaan Manusia, Perspektif Qurani

Maka sesungguhnya kebangkitan itu hanya dengan satu teriakan saja; maka tiba-tiba mereka melihatnya. Dan mereka berkata: "Aduhai celakalah kita!" Inilah hari pembalasan. Inilah hari keputusan yang kamu selalu mendustakannya. (kepada malaikat diperintahkan): "Kumpulkanlah orang-orang yang zalim beserta teman sejawat mereka dan sembahansembahan yang selalu mereka sembah. selain Allah; maka tunjukkanlah kepada mereka jalan ke neraka. Dan tahanlah mereka (di tempat perhentian) karena sesungguhnya mereka akan ditanya. "Kenapa kamu tidak tolong menolong? Bahkan mereka pada hari itu menyerah diri. Sebahagian dan mereka menghadap kepada sebahagian yang lain berbantah-bantahan. Pengikut-pengikut mereka berkata (kepada pemimpin-pemimpin mereka): "Sesungguhnya kamulah yang datang kepada kami dan kanan. Pemimpin-pemimpin mereka menjawab: "Sebenarnya kamulah yang tidak beriman" Dan sekali-kali kami tidak berkuasa terhadapmu, bahkan kamulah kaum yang melampaui batas. Maka pastilah putusan (azab) Tuhan kita menimpa atas kita; sesungguhnya kita akan merasakan (azab itu). Maka kami telah menyesatkan kamu, sesungguhnya kami adalah orang-orang yang sesat. Maka sesungguhnya mereka pada hari itu bersama-sama dalam azab. Sesungguhnya demikianlah Kami berbuat terhadap orang-orang yang berbuat jahat. Sesungguhnya mereka dahulu apabila dikatakan kepada mereka: "Laa ilaaha illallah" (Tiada Tuhan yang berhak disembah melainkan Allah) mereka menyombongkan diri. dan mereka berkata: "Apakah sesungguhnya kami harus meninggalkan sembahan-sembahan kami karena seorang penyair gila? Sebenarnya dia (Muhammad) telah datang membawa kebenaran dan membenarkan rasul-rasul (sebelumnya). (Q.S. Asshoffat, 37: 19)

\section{Zikir darojat, menaikkan derajad orang mukmin}

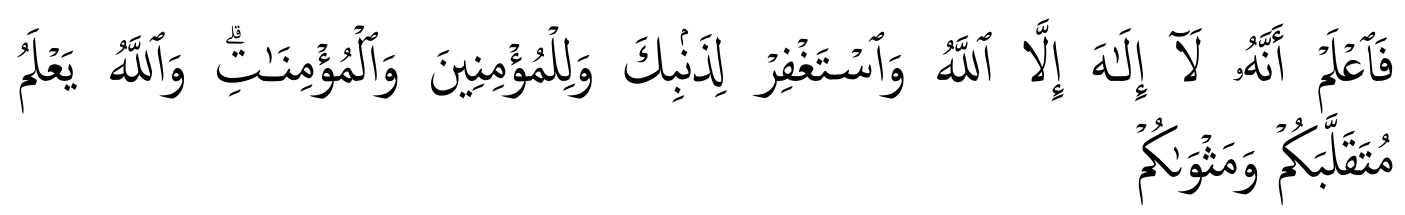

Maka ketahuilah, bahwa sesungguhnya tidak ada Ilah (sesembahan, tuhan) selain Allah dan mohonlah ampunan bagi dosamu dan bagi (dosa) orang-orang mukmin, laki-laki dan perempuan.Dan Allah mengetahui tempat kamu berusaha dan tempat kamu tinggal. (Q.S. Mohammad, 47: 19)

1. orang munafik takut perang, Dan takut kepada orang-orang yang beriman, mereka berkata: "Mengapa tiada diturunkan suatu surat?" Maka apabila diturunkan suatu surat ${ }^{[\mathbf{1 3 9 2}]}$ yang jelas maksudnya dan disebutkan di dalamnya (perintah) perang, kamu lihat orang-orang yang ada penyakit di dalam hatinya memandang kepadamu seperti 
pandangan orang yang pingsan karena takut mati, dan kecelakaanlah bagi mereka.(Q.S. Mohammad, 47: 20)

2. Ta'at dan mengucapkan perkataan yang baik (adalah lebih baik bagi mereka). Apabila telah tetap perintah perang (mereka tidak menyukainya). Tetapi jikalau mereka benar (imannya) terhadap Allah, niscaya yang demikian itu lebih baik bagi mereka(Q.S. Mohammad, 47: 21).

3. Menurut tafsir Syech Abd. Qodir al Jiilani, Q.S. dalam kitabnya SirrulAsror menjelaskan bahwa kalimah tauhid dalam surat Mohammad, 47: ayat 19 di atas status dan fungsi kalimat tauhid tersebut bagi manusia, adalah sebagai pembersih dari dosa, penahan/pelindung bagi manusia dari segala gangguan iblis dan sekutunya untuk membawanya kepada perbuatan dosa. Karena itulah posisi kalimat itu diposisikan sebagai kalimat yang mampu mengangkat derajat manusia ke tempat yang lebih tinggi. Dari pendosa - diampuni, dari syirik - ke ikhlas. Dari kafir - ke mukmin. dari putus - menjadi sambung dengan Allah. Dari jauh - ke dekat dengan Allah.

4. Adam pernah bertindak ma'syiat kepada Allah, yaitu menerjang larangan Allah agar Adam tidak mendekati pohon khuldi, sebaliknya Adam malah memakan buahnya atas bujukan iblis kepada istrinya. diberi Allah sebuah kalimat untuk bertobat dari dosa-dosanya.

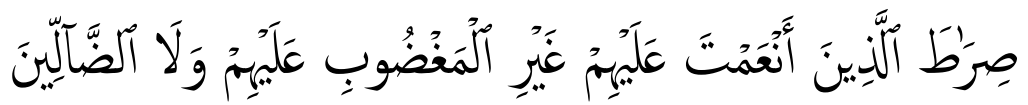

Kemudian Adam menerima beberapa kalimat dari Tuhannya, maka Allah menerima taubatnya. Sesungguhnya Allah Maha Penerima taubat lagi Maha Penyayang(Q.S. Al-baqarah, 2: 37). Kalimat yang dimaksud, menurut Syeh Nashir Makarim Syirozy, adalah kalimat yang disebut AlQuran suarah al-A'rof, ayat 23, keduanya (Adam-Hawa) berkata: "Wahai Tuhan kami, sungguh kami telah mendholimi diri sendiri. Jika Engkau tidak mengampuni kami dan tidak menyayangi kami, maka kami benarbenar menjadi orang-orang yang merugi (QS. Al-A'rof: 23)

Adam bertaubat kepada Allah dengan berzikir terus menerus kepada Allah selama 40 tahun lamanya. Allah yang menentukan apa jenis 
zikirnya, bagaimana caranya berzikir, berapa lamanya/banyaknya dia harus berzikir. Karena semua itu sudah ditentukan oleh Allah SWT.

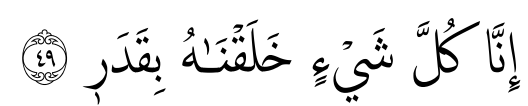

Sesungguhnya Kami menciptakan segala sesuatu menurut ukuran (QS. AlQomar, 54: 49)

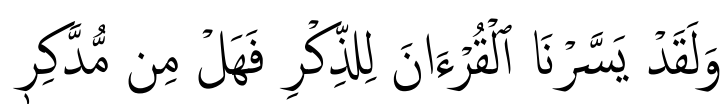

Dan sesungguhnya telah Kami mudahkan Al Quran untuk pelajaran, maka adakah orang yang mengambil pelajaran? (QS. Al-Qomar,54: 40)

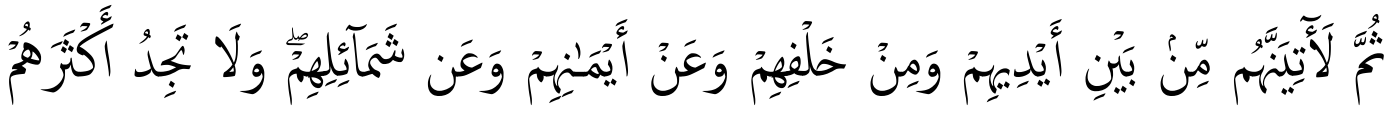

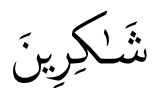

Kemudian saya akan mendatangi mereka dari muka dan dari belakang mereka, dari kanan dan dari kiri mereka. Dan Engkau tidak akan mendapati kebanyakan mereka bersyukur (taat).(QS. Al A'rof, 7: 17).

\section{Allah memberi rekomendasi kepada Ahli Zikir untuk menjelaskan berbagai perkara pelik}

Misalnya tentang status hamba, hubungan antara hamba dengan Tuhannya Cara mendekat kepada Allah, cara berkomunikasi denganAllah tidak banyak yang memahami dengan benar. Allah menyarankan kalau ingin dekat dengan Allah, bagaimana caranya, apa yang harus kita lakukan, kapan dilakukan dst. kita perintah Allah untuk bertanya kepada Ahli zikir (QS. Al-Anbiya, 21: 7). Bukan bertanya kepada ahli kalam, ahli fiqih, ahli hadis dsb., tetapi kita diperintah oleh Allah langsung untuk bertanya kepada Ahli Zikir.

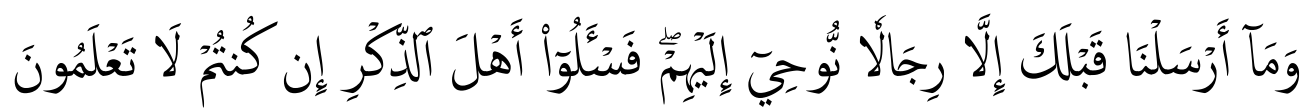
......maka tanyakanlah olehmu kepada orang-orang yang berilmu, jika kamu tiada mengetahui (QS. Al-Anbiya, 21: 7).

Ahli zikir memiliki tugas yang berat. Dipundaknyalah dibebankan keselamatan ruhaniah umat. Dipundaknyalah harus menjelaskan berbagai hal yag berkaitan dengan seluk beluk ruhaniah manusia dalam mendekatkan diri kepada Allah. 
Ayat ini turun sudah 15 abad yang lalu, sampai kini ayat ini belum dimansukh/dihapus oleh Allah SWT .berarti ayat ini masih berlaku sampai sekarang. Impikaasinya adalah Allah-lah yang menjamin eksistensi ahli zikir yang dimaksud. Artinya Allah akanselalu menyiapkan alhi zikir ini sesuai dengan kebutuhan umat islam sepanjang jaman.

\section{Siapa ahli Zikir itu?}

Yang dimasksud dengan ahli zikir dalam ayat tersebut adalah orang yang memahami hakikat zikir yang sebenarnya sebagaimana yang dikehendaki Allah SWT. Ahli zikir diberi kemampuan oleh Allah untuk senantiasa menggunakan hati, lisan, dan seluruh anggota badannya untuk berzikir kepada Allah SWT ahli zikir diberi Allah kompetensi untuk mengajarkan zikir kepada orang lain.

Pertama kali Allah yang mengajarkan zikir kepada Jibril a.s. kemudian Jibril diperintah Allah untuk mengajari Nabi SAW. Selanjutnya Nabi megajarkannya kepada para sahabat-sahabatnya, seperti Ali bin Abi Tholib. Abu Bakar Asshiddiq, Umar bin Khotthob, Usman bin Affan. Ra. Salman Al Farisi, Abdulloh bin Rowahah, Hasan dan Husain r.a. setelah generasi para sahabat ahli zikir menurun kepada ulama-ulama pewaris para Nabi. Menemukan mereka tidaklah mudah, jika tidak dibantu Allah untuk menjumpai para ulama ahli zikir sangat sulit, syaratnya adalah harus sungguh-sungguh mencarinya.

\section{Guru Pembimbing Telah disiapkan Allah sepanjang jaman.}

Siapa yang diberi petunjuk oleh Allah maka dia akan dipertemukan oleh Allah dengan, guru spiritualnya. Sebaliknya siapa yang disesatkan, maka dia tidak akan dipertemukan Allah dengan guru spiritualnya, Dalam Al Quran guru spiritual atau guru pembimbing ini disebut dengan Wali Mursyid.

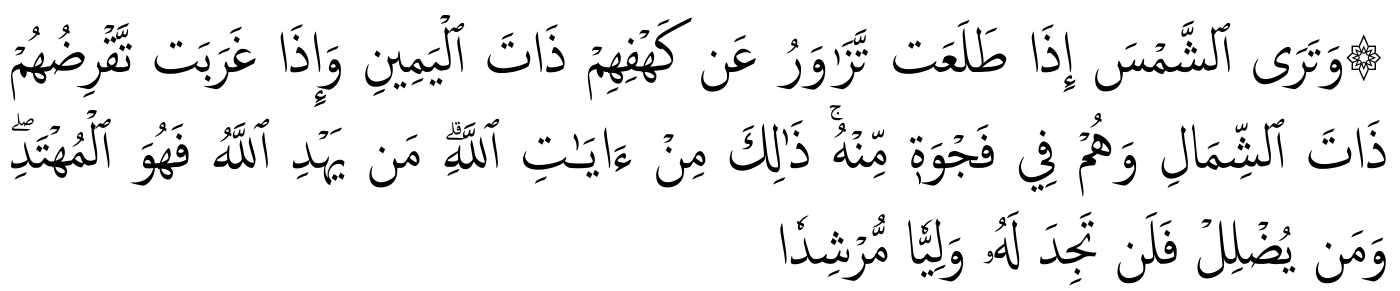

Dan kamu akan melihat matahari ketika terbit, condong dari gua mereka ke sebelah kanan, dan bila matahari terbenam menjauhi mereka ke 
sebelah kiri sedang mereka berada dalam tempat yang luas dalam gua itu. Itu adalah sebagian dari tanda-tanda (kebesaran) Allah. Barangsiapa yang diberi petunjuk oleh Allah, maka dialah yang mendapat petunjuk; dan barangsiapa yang disesatkan-Nya, maka kamu tidak akan mendapatkan seorang pemimpinpun yang dapat memberi petunjuk kepadanya. (QS. Al Kahfi, 18: 17)

Syech Abd Qodir dipertemukan Allah dengan guru pembimbingnya dengan orang penjual sirup di Bagdad. Padahal beliau sudah menjadi ulama besar, namun untuk mengembangkan rohaninya beliau rela dilatih khusus oleh guru spiritualnya selama 20 tahun lamanya. Imam Ghozali karena beliau bersungguh-sungguh berjuang dalam mengembangkan ruhaninya, maka beliau dipertemukan Allah dengan guru ruhaninya. Selama hampir 10 tahun beliau di latih oleh guru spiritualnya untuk benar-benar kenal dekat dan bersikap tawaduk kepada Allah, Padahal beliau secara akademik telah mencapai puncak pada usia 23 tahun. Pada usianya yang masih sangat amat muda, beliau sudah menjadi doktor, guru besar di Perguruan Tinggi Nidhomia di Damaskus, pada jamannya Kekholifahan Islam dibawah Pemerintahan dinasti Bani Saljuk. Beliau telah menjadi rektor dan sudah mengarang beratus ratus bukunya, ternyata beliau belum mencapai perkembangan rohani yang stabil. Atas rahmat Allah beliau dipertemukan Allah dengan guru pembimbingnya yalah tukang shol sepatu di kota Damaskus, Siria.

\section{Analisis dan Pembahasan}

Sebagaimana telah dikemukakan di muka bahwa Ada beberapa faktor yang mempengaruhi kebahagiaan manusia menurut perpektif Qurani antara lain: aAmal sholeh seperti sholat sedekah, membaca quran, dan zikir kepada Allah. Ternyata berzikir kepada Allah merupakan satusatunya cara yang paling efektif dalam mencapai kebahagiaan semua orang, tanpa dibatasi oleh status sosial, ekonomi, politik, latar belakang suku, dan aliran ke agamaan. Semua orang akan dapat mencapai kebahagiaan dengan cara berzikir kepada Allah. Dimanapun dan kapanpun berzikir dapat dilakukan oleh semua orang.

Ada beberapa alasan mengapa berzikir kepada Allah dapat meraih kebahagiaan dengan efektif. 
1. Kebersihan jiwa menjadi faktor datangnya Kebahagiaan. Manusia akan dapat memperoleh kebahagiaannya jika hatinya bersih. Karena itu untuk memperoleh kebahagiaan jiwa atau hati harus dibersihkan dari kotoran hati. Sebagiaman firman Allah sungguh berhagialah orang yang membersihkan jiwanya dan sebaliknya celakalah orang yang mengotori jiwanya (QS. As Syamsi: 8-9).

2. Berzikir kepada Allah merupakan teknik/ cara Pembersih jiwa yang paling efektif. Sebagaimana sabda Rosululloh saw.: "Segala sesuatu ada pembersihnya, dan pembersih hati adalah zikrullah.

3. Ketenangan atau harmoninya jiwa merupakan bagian jiwa manusia yang sangat penting dalam memperoleh kebahagiaan. Hal ini hanya bisa dicapai dengan berzikir kepada Allah swt. Sebagaimana juga ditegaskan oleh Allah SWT. Ketahuilah bahwa hanya dengan mengingat/berzikir kepada Allah sajalah hatimu/jiwamu akan menjadi tenang.

4. Kebahagiaan dan ketenangan manusia berkaitan erat dengan intensitas zikir kepada Allah swt. Artinya semakin intensif zikir yang dilakukan manusia akan dapat meningkatkan ketenangan manusia. Sebaliknya jika manusia tidak berzikir kepada Allah, maka masuklah energi syaithoniyah yang panas dan menyesakkan dada. Sebagaimana yang difirmankan Allah: "Siapa yang hatinya kosong dari berzikir kepada Allah, maka sempitlah dadanya dan diakhirat akan dibangkitkan dalam keadaan buta (QS. Thoha: 124).

5. Orang yang selalu berzikir kepada Allah diwaktu senang dan susah akan dibalas dengan masuk sy urganya Allah tanpa hisab (Hadis yang diriwayatkan oleh Asma r..ha, yang dikutip oleh Maulana Muhammad Zakariya al Kandhalawi.

6. Zikir yang paling efektif dalam meningkatkan kebahagiaan dan ketenangan manusia adalah dengan membaca kalimah tauhid (Laa iLaaha ILLALLAH) yang dibaca d engan keras yang diarahkan pada titik-titik pusat proses spiritual manusia, yaitu di tengah dada, di dahi antara dua alis, di atas kepala, dada kanan atas, dada kanan bawah, 


\section{Pengaruh Zikir Terhadap Ketenangan Dan}

Kebahagiaan Manusia, Perspektif Qurani

terus bergerak ke arah dada kiri bagian atas diakhiri pada dada kiri yang bawah.

7. Berzikir kepada Allah sebagai indikator jiwa yang hidup. Sebagaimana sabda Rosululloh: “orang yang berzikir kepada Allah di tengah-tengah orang yang tidak berzikir adalah bagaikan orang yang hidup di tengah orang yang mati.3 (Syeh Ahmad Shohibul Wafa Tajul 'Arifin, 1970)

Untuk menjaga agar status kebahagiaan hidup di tengah-tengah manusia tetap terjaga, maka manusia perlu mengamalkan zikir dalam hati yang dikenal dengan zikir khofi dengan menyebut asma Allahu Allah ... Allahu Allah dst.

\section{Kesimpulan}

Berdasarkan analisis di atas dapat disimpulan bahwa Kebahagiaan dan ketenangan manusia berkaitan erat intensitas zikir kepada Allah swt. Artinya semakin intensif zikir yang dilakukan manusia akan dapat meningkatkan ketenangan manusia. Sebaliknya jika manusia tidak berzikir kepada Allah, maka masuklah energi syaithoniyah yang panas dan menyesakkan dada.

1. Zikir yang paling efektif dalam meningkatkan kebahagiaan dan ketenangan manusia adalah dengan membaca kalimah tauhid (Laa iLaaha Illallah) yang dibaca d engan keras yang diarahkan pada titiktitik pusat proses spiritual manusia, yaitu di tengah dada, di dahi antara dua alis, di atas kepala, dada kanan atas, dada kanan bawah, terus bergerak ke arah dada kiri bagian atas diakhiri pada dada kiri yang bawah.

2. Untuk menjaga agar status kebehagiaan manusia tetap terjaga, maka manusia perlu mengamalkan zikir dalam hati yang dikenal dengan zikir khofi dengan menyebut asma Allahu Allah....Allahu Allah dst.

\section{Referensi}

'Arifin, Syeh Ahmad Shohibul Wafa Tajul. Miftahus Shudur: Kunci Pembuka Dada. Suryalaya: PT. Mudawwamah Warohmah dan Yayasan Serba Bakti Pondok Pesantren Suryalaya Pager Ageung-,

3 Syeh Ahmad Shohibul Wafa Tajul 'Arifin, Miftahus Shudur: Kunci Pembuka Dada (Suryalaya: PT. Mudawwamah Warohmah dan Yayasan Serba Bakti Pondok Pesantren Suryalaya Pager Ageung, 1970). 
Mohammad Bisri

1970.

---. Uqudul Jumaan, Tanbih. Suryalaya: Yayasan Serba Bakti Pondok Pesantren Suryalaya dan Thoriqat Qodiriyyah Wan Naqsabandiyyah, 1975.

Departemen Agama RI. Al-Quran dan Terjemahannya. Surabaya: Duta Ilmu, 2005.

Yunus, Mahmud. Tafsir Quran Karim. 20 ed. Jakarta: Hidakarya Agung, 1983. 